\title{
POLÍTICA DAS IMAGENS: ESTÉTICA, VISIBILIDADE E DIREITO $^{1}$
}

\section{"Uma máxima brechtiana: 'Não comece das boas coisas velhas, mas das más coisas novas'" \\ ESTÉTICA, DIREITO E POLÍTICA DAS IMAGENS}

Em que pese não ser propriamente uma novidade no campo dos estudos jurídicos, o tema da estética vem despertando um interesse crescente entre os juristas. Centros de investigação em torno da relação entre estética e direito foram criados em diversas universidades e não são poucos os livros e artigos publicados sobre o assunto. Percebe-se que os juristas não apenas estão explorando as fecundas e variadas possibilidades de conexão do direito com mundo das artes e da literatura, mas também estão produzindo reflexões importantes sobre a forma do direito, elemento essencial da juridicidade.

O texto que se segue faz parte desse interesse geral do direito pelo tema
Eduardo R. Rabenhorst ${ }^{2}$ da estética, porém o vocábulo "estética" tem aqui mais relação com o estudo das (experiências sensoriais da percepção do que propriamente com as artes. Em outras palavras, o presente trabalho integra uma linha teórica que, combinando intimamente estética e teoria social, busca entender o papel que a sensibilidade desempenha no funcionamento do corpo social e na existência das pessoas que dele fazem parte (Carnevali, 2013).

Observa Jacques Rancière (2011) que muito embora se diga comumente que a história da arte surgiu com as pinturas rupestres, a arte, enquanto noção que designa uma forma de experiência específica, de traço estético, somente passou a existir no Ocidente a partir do século XVIII. Para tanto, foi necessário ocorrer uma transformação importante não apenas das condições materiais (lugares de representação e exposição, formas de circulação e

\footnotetext{
${ }^{1} \mathrm{O}$ presente trabalho foi financiado com apoio da CAPES, Coordenação de Aperfeiçoamento do Pessoal de Nível Superior através da concessão de bolsa de pós-doutorado (Estágio Sênior) junto à Universidade de Aix-Marselha, França.

${ }^{2}$ Professor Titular de Filosofia do direito da UFPB.
} 
reprodução), mas também do próprio tecido das experiências sensíveis (modos de percepção, regimes de emoção, categorias e esquemas de pensamento).

No entender de Terry Eagleton (2006: 59), a emergência do estético como categoria teórica está, portanto, estreitamente ligada ao processo material pelo qual a produção cultural se tornou autônoma em relação às diversas funções sociais que havia desempenhado tradicionalmente. A estética, com efeito, desponta na Alemanha do século XVIII como resposta ao problema do absolutismo político, introduzindo na Europa monárquica a própria ideia de um julgamento de gosto subjetivo articulado a uma opinião pública.

Nesse sentido, convém lembrar que o teórico alemão Alexander Baumgarten, inventor do substantivo "estética", criado a partir do grego aisthêsis, isto é, a faculdade de sentir, em seu livro homônimo, concebeu essa disciplina como sendo formada por duas partes distintas: a "poética", definida como o conjunto de regras às quais se conformar, e a "gnoseologia" ou ciência do conhecer por meio da sensibilidade, modo "inferior" do conhecimento, já que, de acordo com Baumgarten, não comparável ao conhecimento intelectual.
A história da estética está, portanto, atravessada, desde o início, por essa duplicidade de sentidos, que não passou desapercebida inclusive a Freud. Com efeito, o psicanalista vienense iniciou seu ensaio sobre o "estranho" (Das unheimliche) aludindo exatamente a essa dualidade entre a estética enquanto doutrina do belo, por um lado, e enquanto ciência das qualidades sensíveis, por outro (Freud, 1987).

O sociólogo alemão Georg Simmel é certamente um dos pioneiros na concepção de uma estética sociológica cujo objeto de estudo seria a manifestação sensível do social. Em sua Sociologia dos sentidos (2007), Simmel desenvolveu uma teoria da sensibilidade social construída a partir da observação das interações sensíveis que ocorreriam entre os indivíduos, bem como dos sintomas de "hiperestésia" manifestados pelas pessoas nos contatos físicos mais íntimos.

O sociólogo alemão investigou a moda e os estilos de vida, e utilizou categorias estéticas como "simetria" e "assimetria" na descrição das estruturas sociais. Tratou dos sentimentos de fidelidade e gratidão na coesão das relações sociais e elaborou uma teoria sobre a função sociológica da troca de 
olhares no meio urbano. Para Simmel, as relações entre os homens nas grandes metrópoles seriam caracterizadas pela primazia da visão sobre os outros sentidos. $\mathrm{O}$ desenvolvimento da sociedade de massa e do consumo, os novos fluxos abstratos do dinheiro, tudo isso contribuiria para a imposição de uma forma completamente diferente de percepção sensível e o surgimento de um novo modo de sentir.

Outro autor a trabalhar com a estética em sentido social e a procurar entender as transformações impostas pelas novas tecnologias às experiências de percepção sensível foi Walter Benjamin. Como Simmel, o filósofo alemão também destacou em vários dos seus textos, mas especialmente no livro Passagens (2007), as modificações impostas pela centralidade da visão em diferentes níveis de funcionamento da sociedade no início do século XX (trabalho, lazer, conhecimento etc.) e procurou entender as alterações infligidas aos modos de ser e de sentir dos indivíduos pelas novas funções econômicas e simbólicas das imagens: iluminação artificial, uso de espelhos, arquitetura em vidro e aço, fotografia, moda etc.

Especialmente impactado com o surgimento da reprodução mecânica,
Benjamin sustentou que as formas de perceber e de olhar seriam históricas. $\mathrm{O}$ cinema, por exemplo, ao reproduzir a experiência sensorial cotidiana dos moradores de grandes centros urbanos, teria contribuído para a constituição de uma percepção "distraída" exemplificada na figura do flâneur. Ao julgar do filósofo alemão, a reprodução mecânica, ao tempo em que afetava o caráter único de uma obra de arte, também possibilitava o surgimento de novas formas de ver, perceber e fazer conhecer os objetos artísticos (Benjamin, 2013).

Benjamin foi igualmente um dos primeiros autores a perceber os riscos da estetização social excessiva dos tempos modernos, sobretudo a "estetização da política", fenômeno que, segundo o filósofo alemão, teria surgido a partir do momento em que a arte, considerada autorreferente e autônoma em relação a valores extra estéticos, foi transladada para o campo da política, como ocorreu com o movimento futurista de Marinetti que embelezava a barbárie e a guerra. A estetização da política, no entender de Benjamin, decorreria da alienação sensorial praticada pelo fascismo. Contra a estetização da política Benjamin propugnou a "politização da arte", sem, 
contudo, explicitar os detalhes dessa ideia. Para Susan Buck-Morss (2010), entreanto, é possível conceber que o filósofo alemão estivesse pensando na possibilidade de uma arte capaz de romper a alienação do sensório corporal e restabelecer a força instintiva dos sentidos.

$\mathrm{Na}$ contemporaneidade, um dos autores que mais tem trabalhado com o tema da "política estética" é Jacques Rancière. O filósofo francês traçou em sua obra uma diferença entre os conceitos de "polícia" (police) e "política" (politique). No entender de Rancière, a "polícia" seria a instância encarregada de estabelecer e manter a ordem e o consenso, enquanto a "política" seria a dimensão que instauraria a resistência e o dissenso. Para o filósofo francês, a política e arte se encontram conectadas na medida em que as representações visuais não podem ser comunicadas e repartidas na cena pública sem as normas sociais, estéticas e políticas que funcionam como limites discursivos e de visibilidade no âmbito de uma sociedade e época.

Daí a ideia de Rancière de que há "regimes de visibilidade" distintos, diferentes maneiras de se distribuir $o$ visível. Tais regimes seriam historicamente situados, dependeriam de uma série de instituições e estariam submetidos à lógica do poder político, ou seja, cada sociedade decidiria, em uma situação dada, utilizando um meio específico, operar sua partilha do visível. Assim, enquanto a "polícia" instituiria a percepção social dominante e o consenso, a "política" instauraria atos de resistência, buscando reconfigurar a repartição do sensível. No entender de Rancière, portanto, a arte não é política em razão de seu conteúdo ou por conta de seu engajamento social. A arte é política na medida em que estabelece no âmbito da esfera pública um conflito entre regimes sensoriais diferentes e contribui assim para o desenhar de novas formas do visível, do dizível e do pensável.

A partir dos exemplos de Simmel, Benjamin e Rancière, aos quais poderiam ser somados outros autores, tais como Lucien Febvre e Erving Goffman, percebe-se que a estética social é um instrumento importante não apenas para analisar as modificações sofridas pelo sensório humano com a experiência moderna, mas também para interpretar a visibilidade como um campo de lutas por representação em que existem, ao mesmo tempo, processos de 
estetização, na acepção de tornar visível um elemento, e processos de (des)estetização, no sentido de insensibilização ou de subtração de um elemento da percepção sensível coletiva. A estética social enseja, assim, uma linha de interpretação da seleção que uma sociedade faz das imagens aceitas e daquelas que são prescritas ou marginalizadas, e consequentemente um entendimento de que como se dá a repartição política do visível e do invisível no espaço comum.

\section{CULTURA VISUAL E DIREITO}

Vivemos em uma época que parece ter se entregado por completo à visibilidade. Do ponto de vista da subjetividade, faz-se presente em nossos dias uma exigência permanente de exposição pública e de produção contínua de representações visuais, um imperativo de espetáculo e transparência, de ver e de se fazer visível, de captar a atenção, sobretudo com ajuda dos meios de comunicação e das novas plataformas digitais de difusão. Aparentemente, todos querem exercer um "direito" de expressão na suposta esfera pública dos meios visuais.
Essa injunção da visibilidade na sociedade contemporânea, ou melhor, de uma hipervisibilidade, ocorre em concomitância com o surgimento de uma cultura das telas, essas superfícies de comunicação, agora também sensíveis ao toque, que mostram e projetam imagens. Televisão, computador, smartphone, GPS e tantos outros suportes, o tempo que doravante o indivíduo consagra aos painéis eletrônicos é realmente vertiginoso. $\mathrm{O}$ acesso ao visível se dá assim cada vez mais por meio de imagens que são suportes fundamentais da representação visível e meios de transporte de afetos e pulsões. A era da visibilidade é coetânea ao surgimento de uma sociedade dominada pela imagem visual.

Conforme observou Horst Bredekamp (2010), as imagens em nossa época formam uma verdadeira "economia", no sentido mais amplo do termo. Elas movimentam um gigantesco setor econômico constituído pela indústria do entretenimento e a publicidade. As imagens são também aliadas importantes do poder e influenciam as ações políticas e de consumo. São armas de guerra no mundo militar, arquivos que guardam a memória dos acontecimentos, meio de análise e 
diagnóstico na área médica, e objeto de um arsenal jurídico sem precedentes. A era das imagens é também a do capitalismo "hiperespecular".

As imagens estão em toda parte. Nos espaços públicos e privados, nas telas, nos monumentos figurativos, nas esculturas, nos outdoors, nas projeções luminosas, nos cartazes, no mobiliário urbano, as imagens se reproduzem ao tempo em que produzem aparências políticas, publicitárias, sociais e estéticas. Essa presença excessiva não significa, contudo, que as imagens estejam efetivamente sendo vistas. Em razão da eficiência dos novos meios disponíveis, a visão parece ter se tornado ótima, integral, completa, transparente, mas por isso mesmo também saturada pela constância de imagens que finalmente não são visíveis.

É possível, suspeita Camiel van Winkel (2014), que a visibilidade descomedida e a inflação icônica tenham finalmente esvaziado o indivíduo da capacidade de ver. Nesse sentido, observa Marie-José Mondzain (2009), na era em que a visibilidade é abundante, a

\footnotetext{
${ }^{3}$ Alain Mons (2002), por sua vez, sugeriu que tudo não passaria de uma questão de cintilância. No entender de Mons, a superposição imanente de imagens na era atual torna o visível cintilante, faz com que ele apareça e despareça continua e
}

imagem corre o risco de desaparecer sob a violência dos fluxos que a esgotam. A profusão de imagens de refugiados em balsas improvisadas ou afogados, imagens de bombardeios e massacres, imagens de crianças amputadas, não nos tornam menos indiferentes ao que acontece a essas pessoas nem conseguem suscitar nossa intervenção, como bem percebeu Susan Sontag (2003) ${ }^{3}$.

A presença maciça das imagens ensejou um interesse crescente pela linguagem visual. A partir do início da década de 1990, autores como Gottfried Boehm e Wiliam J. T. Michell, romperam com a visão tradicional de que as imagens serviriam apenas para criar prazer em detrimento da sua capacidade de produzir conhecimento e sustentaram a necessidade da filosofia e das ciências sociais refletirem sobre a abundância das imagens no mundo contemporâneo. Michell propôs, inclusive, que após o linguistic turn, que caracterizou o pensamento no século XX, teria chegado agora o momento de um visual turn, isto é, de uma virada teórica que atribuiria ao

rapidamente, de maneira que a postura do sujeito contemporâneo já não é mais a de um "vidente" das coisas, mas tão somente a de um "entrevidente" delas. 
visual ou ao icônico, o papel de tópico central das discussões.

Apesar do interesse dos juristas pelas questões atinentes à imagem desde o surgimento da fotografia e do cinema, e mais recentemente pelos problemas específicos suscitados pelo surgimento das imagens numéricas, a "virada visual" no âmbito do direito ainda é tímida. Não são muitos os trabalhos que enfatizam os aspectos mais teóricos do tema das representações visuais. A maior parte das publicações, quase sempre situadas em rubricas como "direito e arte" ou "direito e cinema", buscam muito mais entender como as imagens influenciam a percepção de conceitos fundamentais do direito. Contudo, outras pistas de trabalho têm surgido nos últimos anos, especialmente entre os teóricos do direito afinados com os temas da filosofia política e da escrita do direito.

Assim, por exemplo, o alemão Horst Bredekamp publicou um estimulante livro sobre o frontispício do Leviatã de Thomas Hobbes, em que retraçou a gênese das imagens do Estado-Monstro empregadas pelo filósofo inglês. Outros autores (Medina, 2006) têm explorado o potencial epistemológico das imagens em processos políticos, especialmente no nível de seus efeitos e funções comunicativas. No âmbito específico da escrita do direito, pode-se citar o filósofo espanhol do direito José Calvo, que publicou um ensaio sobre imagens resgatadas do códice inglês Smithfield Decretals, destacando a importância de se estudar a cultura visual como meio de expressão do direito (Calvo, 2016).

Mas existem outros aspectos dos temas da visibilidade e das imagens na cultura contemporânea ainda pouco explorados pelos teóricos do direito. Com efeito, não estaria a visibilidade ligada às reivindicações contemporâneas de reconhecimento social, como também ao "direito de olhar" e ao "direito de aparecer"? Pode-se entender, portanto, a visibilidade, enquanto fenômeno estético e político, como um ato de justiça?

\section{VISIBILIDADE $\quad$ E $\quad$ DIREITO: RECONHECIMENTO, ESPETÁCULO E VIGILÂNCIA}

Alguns autores empregam o vocábulo "visualidade" para designar a forma de organização social e histórica da percepção visual, da regulação das funções da visão e de seus usos epistêmicos, estéticos, políticos e morais. A visualidade se refere, portanto, 
aos "modos de ver" cultural e historicamente construídos. Contudo, não há consenso entre os autores sobre a emergência dessas construções nem mesmo quanto ao papel delas na vida visual dos seres humanos.

Anne Sauvageot (1994), por exemplo, diferencia o dado físico que é percebido pela vista, ligado às capacidades físicas de nosso sentido visual e às propriedades espaciais e temporais das circunstâncias nas quais o visualizador se encontra (campo de visão), da visualidade propriamente dita, que diz respeito aos mecanismos socioculturais partilhados que constituem e regulam os modos de ver e as experiências visuais, isto é, às estratégias que transformam a percepção psicofísica em fluxo propriamente significativo. $\mathrm{O}$ que se busca destacar com a ideia de visualidade é que os diversos grupos humanos elaboram maneiras diferentes de visualizar e de representar visualmente a realidade (modelos de visibilidade, agentes, processos e objetos).

A representação visual é a maneira como através de determinadas convenções, instrumentos e técnicas, o mundo é refletido visualmente. Embora uma representação visual seja produzida por um autor específico, ela reflete não somente esse conjunto de convenções e instrumentos, mas também as relações existentes entre aquele que representa e o objeto que é representado. Os processos sociais, porém, determinam a representação, mas de algum modo são também influenciados ou alterados por ela. Com efeito, as representações "informam" nos dois sentidos da palavra: por um lado elas transmitem uma informação, mas por outro lado elas “dão formam”, isto é, elaboram ou constroem essa mesma informação. Uma imagem, como diz Patrick Vauday, é um signo com um poder específico de fazer ver, de colocar formas em cenas, espaços e formas que ela oferece ao olhar. Uma imagem, portanto, não reproduz o visível, mas o produz e o configura (Vaudray, 2008:143). Por isso, não faz qualquer sentido questionar a "verdade" das representações visuais. Mais importante é procurar entender a genealogia causal delas, saber por quem e como são elaboradas, como são utilizadas e compartilhadas no espaço comum.

A visualidade não se confunde com a visibilidade, embora estejam interligadas. Como mostra Nathalie Heinich (2012), o termo visibilidade 
denota no âmbito das ciências sociais as ideias de reconhecimento, publicidade e "observalidade". Em uma linha de raciocínio similar, Andrea Brighenti (2007), por sua vez, estabeleceu uma distinção entre três sentidos do termo visibilidade: "visibilidade social", associada ao reconhecimento de direitos; "visibilidade mediática", conexa à exposição e à difusão de imagens; e visibilidade enquanto controle, ligada à vigilância.

Brighenti tem procurado mostrar que a visibilidade faz confluir o ato físico de ver, as novas tecnologias do visual e os elementos e discursos que elaboram o que é a visão, ou seja, que a visibilidade conjuga relações de percepção (aspecto estético) com relações de poder (aspecto político). Para o sociólogo italiano, os efeitos da visibilidade dependem de arranjos territoriais, relacionais, organizacionais e tecnológicos particulares, o que evidencia o papel importante que desempenha o direito nesse processo enquanto modalidade de simbolização da ação humana por intermédio de normas (Brighenti, 2009).

$\mathrm{Na}$ visibilidade estão conectados o ato físico de ver, as novas tecnologias do

\footnotetext{
4 No entender de Honneth (2005), há dois momentos que configuram $\mathrm{o}$ ato de
}

visual e os elementos discursos que elaboram o que é a visão, ou seja, a visibilidade é um fenômeno ao mesmo tempo estético e político, visto que conjuga relações perceptivas com relações de poder (Brighenti, 2013). Entender o fenômeno da visibilidade exige, assim, uma análise do complexo jogo existente entre a visão, o olhar, a visualidade, os aparelhos, as instituições, os discursos, as práticas de observação etc. Requer também uma compreensão da construção política do visível, de sua gestão e de sua partilha entre os sujeitos no espaço comum.

Com efeito, a capacidade de ver e de ser visto não repousa apenas em qualidades naturais, mas é algo que depende largamente de regras sociais, podendo inclusive se transmutar em exigência política em torno da qual os atores individuais e coletivos entram em confronto (Voirol, 2005). A luta por visibilidade, nesse sentido, conforme observou Axel Honneth (2004), é parte da "luta por reconhecimento", ainda que "ser visível" não seja garantia de ser "reconhecido" $"$.

No âmbito de uma sociedade liberal, quando indivíduos ou grupos são 
invisíveis, seja de modo absoluto ou de modo relativo, isso significa, do ponto de vista jurídico, que as estruturas legais criadas para promover a liberdade e a igualdade não funcionam ou que elas funcionam com menos eficácia e rigor quando se trata de determinados segmentos. A invisibilidade social é um caso típico. Ela remete à ausência de reconhecimento social de públicos pobres, excluídos dos espaços de representação e de participação cidadã, tal como acontece com as pessoas expostas à situação de rua.

A invisibilidade social, além de denegar a participação justa dos grupos na cena pública, serve para reforçar ideias estereotipadas acerca de seus membros. Muitos dos movimentos em favor de direitos de um determinado grupo sociocultural são movimentos por visibilidade. Do mesmo modo, muitas violações de direitos humanos estão conectadas à questão da visibilidade: mulheres, pessoas com deficiência, pessoas expostas à situação de rua, detentos, doentes mentais internados, imigrantes etc. Daí a pertinência de se

é visto pelo outro a partir de suas características particulares, e o momento da expressão, quando falar, ao menos prima facie, de uma visibilidade "justa" ou "injusta".

Mas é preciso observar, no entanto, que a visibilidade não opera sem ensejar ambivalência, o que torna a discussão bastante complexa. Como mostraram N. Aubert e C. Haroche (2008), alguns grupos sociais, por exemplo, são invisíveis sob certo ângulo, porém eles são excessivamente visíveis sob outro prisma. O caso das mulheres é bastante ilustrativo. Invisíveis do ponto de vista político, por exemplo, elas são, em contrapartida, excessivamente "visíveis" nos meios de comunicação e na publicidade, porém no mais das vezes a partir de representações visuais que reforçam estereótipos de gênero. O que ocorre, portanto, é que em muitas situações sociais não há “intervisibilidade", isto é, reciprocidade da visão, como bem mostram os exemplos do "olhar médico" descrito por Foucault no Nascimento da Clínica (Foucault, 1977) e as análises do male gaze feitas pela crítica feminista do cinema (Mulvey, 1975 e 2004).

O mesmo pode ser dito em relação a outras manifestações da

ocorre a demonstração pública deste reconhecimento. 
visibilidade operadas pelos meios de comunicação que manipulam códigos de representação e expõem a vida íntima e os laços afetivos na vida pública: reality shows, revistas de celebridades, redes sociais etc. Para além das questões de ordem social, estética e até mesmo psicanalíticas, há efeitos políticos e jurídicos nesses processos que deveriam interessar aos juristas, notadamente questões de justiça ligadas à representação mediática e a maneira pela qual o direito considera atualmente os chamados "direitos morais" (direito ao nome, direito à imagem, direito ao respeito à vida privada etc.).

Observa Brighenti (2013) que o espaço público não é apenas o espaço de acesso comum que possibilita a discussão racional, mas é também o espaço de "afecções", de impressões afetivas que conduzem à ações irrefletidas. No domínio da afetividade nunca é possível excluir os efeitos afetivos ambivalentes ou incontroláveis advindos com a visibilidade de um grupo. Nesse sentido, a visibilidade reivindicada como direito é sempre uma via de mão de dupla, podendo se transformar em espetáculo, o que enseja distorções no processo de reconhecimento. Por outro lado, prossegue Brighenti, é importante reconhecer que a visibilidade não depende apenas daquele que vê, mas igualmente daquele que é visto. Por isso, para alguns grupos sociais a visibilidade é ameaçadora.

Por outro lado, Judith Butler, analisando os movimentos contemporâneos de ocupação política de espaços públicos, e a tensão existente entre a forma política da democracia e o princípio de soberania popular, destacou o fato de que a política é também a força que torna visível as reivindicações no espaço público, de modo a reconfigurálo em seus limites políticos e mediáticos. Dessa forma, nas ocupações e assembleias, a aparição de corpos "precarizados", ordinariamente excluídos do espaço publico, já é uma contestação de quem tem o "direito de aparecer" e de se expressar publicamente.

Nesse sentido, não se pode perder de vista de que a visibilidade é antes de tudo um dispositivo de poder. Para Nicholas Mirzoeff (2011), a visibilidade tem a ver primeiramente com vigilância, isto é, com as formas de disciplinar, normalizar e ordenar a visão. A visibilidade, diz Mirzoeff, está historicamente relacionada com a 
plantação escravista e o exército moderno. Nos dois casos, a ideia é a mesma: trata-se da visibilidade como forma de conhecimento absoluto do outro, forma assimétrica de visualização na qual não há reciprocidade do olhar.

Contra essa articulação entre visibilidade e poder, Mizoeff reivindica um "direito de olhar", isto é, uma "contra-visualidade" que consistiria não apenas em ver as imagens de modo distinto, mas principalmente em criar estratégias de desarticulação do sistema hegemônico de visualização. A "contravisualidade" estabeleceria um olhar mais igualitário, relacional e recíproco. $\mathrm{Na}$ mesma linha, Laura Mulvey, após ter mostrado em um texto clássico como funciona o "olhar masculino" (male gaze) no cinema hollywoodiano a partir do movimento das câmeras sobre as atrizes, tem procurado identificar a possibilidade de existência de um contracinema capaz de produzir imagens alternativa das mulheres e gerar outra forma de olhar (Mulvey, 1975 e 2004).

De todo modo, convém ter clareza de que ser reconhecido pelo outro pode significar também ser observado por ele. Com efeito, a injunção da visibilidade na sociedade contemporânea está ligada ao controle e à vigilância das pessoas, especialmente de determinados grupos de indivíduos (Mattelart et Vitalis, 2014). No entender de Brighenti, por exemplo, na contemporaneidade está em curso uma reordenação dos regimes de visibilidade que amplia consideravelmente a margem do visível (satélites, tecnologias de geolocalização e de visualização miniaturizadas, microscópios etc.), ao tempo em que expande o monitoramento e a vigilância nos espaços públicos e privados, algo que importa em demasia ao direito.

Já Foucault havia alertado para essa onipresença dos dispositivos de controle e registro na sociedade contemporânea. Os estudos contemporâneos sobre visibilidade, entretanto, vão mais adiante $\mathrm{e}$ acrescentam um aspecto não previsto por Foucault. O sociólogo do direito Thomas Mathiesen (2013), por exemplo, acrescenta ao modelo foucaultiano do panóptico, isto é, a vigilância que poucos exerceriam sobre muitos na sociedade disciplinar, o modelo do sinóptico como novo mecanismo de poder. Para Mathiesen, embora em diversas situações contemporâneas muitos indivíduos continuem a observar outros poucos, as novas tecnologias de informação e comunicação também 
permitem que muitos vigiem a poucos, como acontece na televisão e na web.

$\mathrm{Na}$ sociedade atual, entende Mathiesen, a vigilância e o registro se tornaram tão banais quanto desejáveis, incidindo sobre muitos objetos diferentes: dados, meta-dados, perfis, estilos de vida etc. O fenômeno global da observação ensejado pelo ciberespaço "democratiza" e inverte o controle: além da multiplicidade de meios de vigilância (câmeras, chips, drones, reconhecimento facial biométrico etc.), os observados são agora também observadores recíprocos ávidos em verem e serem vistos. O panóptico e o sinóptico operam em conjunto nos dias atuais.

Contudo, esta a possibilidade de uma ambivalência interessante no uso das tecnologias vigilantes que recebe o nome de "sousveillance" (Mann, 2004). $\mathrm{O}$ neologismo remete à palavra francesa "surveillance", que designa vigilância. $O$ prefixo "sur" em francês, indica algo que está por cima (sobre), enquanto o prefixo "sous", nomeia o que está por baixo (sob). Em decorrência das novas tecnologias, todos são vigiados, sem que se saiba ao certo, nessa estrutura de transparência, quem vigia que. Assim, a "sousveillance", portanto, seria uma contra-vigilância que reduziria as disparidades entre quem controla e quem é controlado.

Como observa Gonzalo Abril Curto (2010), não existe ordem política que não tenha sustentado e expressado um regime de visibilidade, administrando o olhar e definindo o que pode ser visto e o que deve permanecer invisível. $\mathrm{O}$ poder, em qualquer sociedade, requer uma "mise en scène", uma teatralização, conforme já havia assinalado Georges Balandier (1980). A novidade dos dias de hoje está no fato de que a atividade política passou a se desenvolver na esfera de uma visibilidade pública cada vez mais controlada pelos meios de comunicação, operando a partir de uma lógica publicitária. A política passou a funcionar de modo semelhante aos produtos da indústria cultural, buscando captar a atenção do público no placo mediático, através de jogos e lutas simbólicas.

Por isso, o espetáculo, no sentido atribuído à expressão por Guy Débord (1997), passou a ser outro aspecto da visibilidade, essencial para a manutenção do poder disciplinar na sociedade contemporânea. O espetáculo, no entender de Debord, tem dois sentidos que estão articulados, indicando tanto a 
centralidade da mercadoria no capitalismo avançado, quanto a transformação do real em imagens, isto é, a autonomização da representação frente à realidade: "O espetáculo é o momento em que a mercadoria ocupou totalmente a vida social. Não apenas a relação com a mercadoria é visível, mas não se consegue ver nada além dela: o mundo que se vê é o seu mundo".

Ora, quais seriam as implicações decorrentes dessa espetacularização da política nos processos de tomada de decisões? Se, como diz Jacques Rancière (2000), a política ocupa-se "do que se vê e do que se pode dizer sobre o que é visto", de que forma, portanto, os modos de ver e ser visto interferiram nos processos decisórios?

Primeiro, é preciso entender a própria transformação do espaço público como âmbito que organiza a experiência social no mundo contemporâneo. $\mathrm{O}$ desenvolvimento de dispositivos tecnológicos de mediação ensejou uma nova forma de comunicação que além de ter tornado a esfera pública muito mais complexa em termo de variedade, também a fez funcionar a partir de uma grande heterogeneidade de situações de interação, ampliando as formas tradicionais de visibilidade. No entender de John B. Thompson (1999), por exemplo, esse novo cenário afetaria radicalmente a democracia em pelo menos dois grandes aspectos.

Em seu célebre livro sobre as promessas não cumpridas da democracia, Bobbio (1986) afirma que esta nasceu com o propósito de fazer desaparecer o poder invisível, colocando em seu lugar um poder transparente, cujas decisões seriam sempre visíveis e controláveis por todos. Em que pese a crescente exigência contemporânea de exercício público do poder, que se dá por meio de uma série de conceitos e práticas (transparência, prestação de contas, acesso à informação etc.) a imagem fortemente confiante da visibilidade na democracia vem sendo abalada pela forma como a visibilidade é mediatizada pelos meios eletrônicos. No entender de Thompson, esses meios, que não são apenas canais de transmissão da informação, mas elementos geradores de novas formas de ação e de interação. Ao tempo em que ensejam maior capacidade de controle pelos cidadãos, produzem novas fragilidades sociais e demandas políticas incompatíveis, tais como a exigência de administrações totalmente abertas, por um lado, e a existência líderes fortes e confiáveis, por outro. 
Periódico do Núcleo de Estudos e Pesquisas sobre Gênero e Direito

Centro de Ciências Jurídicas - Universidade Federal da Paraíba V. 6 - $\mathrm{N}^{\circ} 02$ - Ano 2017

ISSN | 2179-7137 | http://periodicos.ufpb.br/ojs2/index.php/ged/index
Brighenti também tem procurado destacar outras distorções provocadas pela injunção das novas formas de visibilidade na democracia contemporânea, em especial o retorno da "multidão". No entender de Brighenti, o grande debate sobre a multidão no século XIX representou uma tentativa de entender a nova situação social, espacial e material advinda com o desenvolvimento urbano das grandes metrópoles, o que produziu um conjunto de saberes sobre a multidão. Hoje, é preciso igualmente fazer frente a uma nova multidão que se configura antes de tudo como uma multidão de dados ensejada pelas novas tecnologias da informação e da comunicação. A nova multidão, entende o autor italiano, é pósurbana e pós-humana: posts, comments, likes, tweets, feeds etc. Entretanto, tal como ocorria com a multidão do século XIX, essa profusão caótica de dados é a constatação de um todo social confuso e de uma visibilidade fortemente hierarquizada (2011).

Mas é preciso também reconhecer os novos arranjos e possibilidades da esfera pública advindos na contemporaneidade. Mesmo não atendendo a todas as exigências para se falar de uma efetiva discussão pública, as novas tecnologias virtuais possuem uma capacidade enorme de conectar indivíduos em redes que ultrapassam as limitações tradicionais de espaço e de tempo impostas às discussões off-line. Por outro lado, ao contrário dos meios de comunicação da época do apogeu da televisão, os novos meios virtuais possibilitam uma comunicação direta da informação política, sem intermediários, proporcionando que o publico possa, ao menos em tese, exercer um papel ativo e não o papel de simples apreciador do jogo político.

\section{CONSIDERAÇÕES FINAIS}

O objetivo deste texto, fortemente exploratório, foi destacar alguns aspectos do tema da visibilidade que podem ser explorados pelo direito a partir das contribuições oferecidas pelos estudos sobre estética social e cultura visual. Embora esses estudos ainda configurem um campo disciplinar emergente, eles estabelecem estimulantes perspectivas sobre as dinâmicas sociais e políticas da visibilidade. $\mathrm{O}$ que aqui se procurou destacar foram alguns temas que oferecem aos juristas, especialmente aqueles interessados nas áreas da 
sociologia do direito e dos direitos humanos, possibilidades promissoras de intervenção.

\section{REFERÊNCIAS}

Abril, Gonzalo. (2013). Cultura visual, de la semiótica a la política. Madrid: Plaza y Valdés, 2013. . (2010). Cultura visual y espacio público-político. Cuadernos de Información y Comunicación, vol. 15 21-36.

Aubert, Nicole e Harouche, Claudine. (2011). Tyrannies de la visibilité. Être visible pour exister? Paris: ERES.

Balandier, Georges. (1980). Pouvoir sur scène. Paris: PUF.

Benjamin, Walter. (2013). L'GEuvre d'art à l'époque de sa reproductibilité technique. Paris, Payot.

(2007). Passagens.

Belo Horizonte: UFMG.

Bobbio, Norberto. O futuro da democracia (uma defesa das regras do jogo). Rio de Janeiro, Paz e Terra.

Brighenti, Andrea. (2007). Visibility: A Category for the Social Sciences, Current Sociology, n. 55, May, p. 323342.

(2009). Pour une territoriologie du droit, In: FOREST,
Patrick (Dir.) Géographie du droit. Épistémologies, développements et perspectives. Québec: Presses de l'Université Laval, pp. 239-260.

(2011). Le nuove politiche di visibilità in rete. Cosmopolis. Revista di filosofia e teoria politica, VI/2. (2013). La démocratie a l'heure des visibilités hiérarchisées. In: Fabre, Thierry. La cité en danger. Dictature, transparence et démocratie. Rencontres d'Averroès 19, Marseille: Éditions Parenthèses.

Van Winkel, Camiel. (2005). The regime of visibility, Rotterdam, Nai Publishers.

Carnevali, Barbara. (2013) L'esthétique sociale entre philosophie et sciences sociales. Tracés. Revue de Sciences Humaines, $\mathrm{N}^{\circ} 13$.

Crary, Jonathan. (1992). Techniques of Observer. On vision and modernity in the XIX century. Massachusetts, MIT Press.

Debord, Guy. (1997). A sociedade do Espetáculo. Rio de Janeiro:

Contraponto.

Eagleton, Terry. (2006). La estética como ideologia. Madrid: Trotta. Freud, Sigmund. (1987). L'Inquiétant étrangeté. Paris: Hatier. 
Fiserova, Michaela. (2013) Partager le visible. Repenser Foucault. Paris: L'Harmattan.

Foucault, Michel. (1977). O Nascimento da clínica. Rio de Janeiro: Forense.

Foucault, Michel. (1987). Vigiar e Punir: nascimento da prisão. Petrópolis: Vozes.

Haroche, Claudine (2008). A condição sensível. Rio de Janeiro: Contracapa.

Heinniche, Nathalie. (2012). De la visibilité. Excellence et singularité em régime médiatique. Paris: Gallimard.

Honneth, A. (2005). La lutte pour la reconnaissance. Paris: Éditions le Cerf. Honneth, A. (2004). «L'invisibilité: sur l'épistémologie de la reconnaissance». Réseaux, vol. 23, n. 129-130, p. 41-57. Jay, Martin. (1996). Introduction: Vision in context : reflections and refractions. In : Brennan, T; Jay, Martin. (Ed.) Vision in context: historical and contemporary perspectives on sight. New York/London: Routledge.

Mathiesen, Thomas (1997). The viewer society: Michel Foucault's "Panopticon" revisited". The viewer society, 1 (2), pp. 215-232.

Mattelart, Armand et Vitalis, André (2014). Le profilage des populations.

Paris: La découverte.
Medina, Cuauhtémoc (Ed.). (2006). La imagem politica. México: Universidad nacional Autónoma de Mexico. Instituto de investigaciones estéticas.

Mirzoeff, Nicholas. (1998). Visual Culture Reader. London: Routledge. Mirzoeff, Nicholas. (2011). The Right to Look: A Counterhistory of Visuality. Durham, NC: Duke University Press Books.

Mondzain, Marie-José. (2009). Repenser l'esthétique, pour une nouvelle époque du sensible. In: Ton, Colette. Esthétique et Société. Paris, L'Harmattan.

Mulvey, Laura. (1975). "Visual Pleasure and Narrative Cinema." Screen, v. 16, n. 3, p. 6-27.

(2004). "Looking at the Past from the Present: Rethinking Feminist Film Theory of the 1970s." Signs. Journal of Women in Culture and Society, v. 30, n. 1, Autumn 2004. p. 1286-1292.

Rancière, Jacques. (2000). Le partage du sensible. Paris: La Fabrique.

(2011). Aisthesis.

Scènes du régime esthétique de l'art. Paris : Éditions Galilée.

Sauvageot, Anne. (1994). Voir et Savoirs. Esquisse d'une sociologie du regard », PUF. 
Simmel, Georg. (1989). Les grands

villes et la vie de l'esprit. Suivi de

Sociologie des Sens. Paris: Payot.

(2007). Esthétique

sociologique. Laval: Les Presses de

l’Université de Laval.

Sontag, Susan. (2003). Diante da dor

dos outros. Rio de Janeiro: Companhia

das Letras.

Talon-Hugon, Carole. (2014). L'Art

victime de l'ésthétique. Paris:

Hermann.

Thompson, J. B. (1999). A mídia e a

modernidade: uma teoria social da

mídia. 2a ed. Petrópolis: Vozes.

Vaudray, Patrick. (2008). L'Invention

du visible. L'Image a la lumière des arts,

Paris: Hermann Éditeurs.

Voirol, Olivier. Visibilité et invisibilité:

une introduction. Reseaux, $\mathrm{n}^{\circ}$ 129-130,

2005, p. 9-36. 